\title{
Causes of Partial or Complete Reversibility of Martensitic Transformation in Alloys of Iron
}

\author{
G. Kubla and E. Hornbogen \\ Ruhr-Universität Bochum, Institut für Werkstoffe, 44780 Bochum, Germany
}

\begin{abstract}
Martensitic transformation implies a change in crystal structure by lattice variant shear as well as the formation of lattice defects by various amounts of lattice invariant shear. Crystallographic reversibility defines conditions under which the reverse reaction leads to the restoration of a defect-free high temperature phase $(\gamma)$. This requires a lattice variant shear in opposite direction to the previous martensitic transformation. As alloys of iron are usually non-reversible a systematic study has been conducted to define the parameters which favour reversibility.

Different $\mathrm{Fe}$-Ni-based alloys have been studied to explore the effects of heating rates and alloying elements. The course of the retransformation is followed by DSC investigations. Optical and TEM investigations have been done to describe the change of macro- and microstructure after retransformation.
\end{abstract}

\section{Introduction}

Since the shape- memory effect has been found in alloys of iron many investigations have been conducted to optimize the effect. However, less interest is spent on a general understanding of the origin of crystallographic reversibility in alloys of iron.

The retransformation from martensite into austenite in Fe-based alloys is usually characterized by an irreversible course of the transformation. As a result, both macro- and microstructure become different compared with the initial one. But under certain conditions the $\alpha_{d}-\gamma$ - transformation will lead to a restoration of the high temperature phase $(\gamma)$ without any lattice defects. A prerequisite for this $\alpha_{\mathrm{d}}-\gamma$ - transformation is a lattice variant shear in opposite direction to the previous martensitic one $\left(\gamma_{\gamma-\alpha d}=\gamma_{\alpha d-\gamma}\right)$. The crystallographic reversibility is a prerequisite for the development of an iron- based shape memory alloy.

A detailed knowledge is important to describe the conditions which favour the complete reversibility. Therefore investigations have been conducted systematically to explore different parameters which may influence the retransformation. discussed.

The change in macro- and microstructure as well as the transformation temperature are 


\section{Experimental Procedures}

$\mathrm{Fe}-\mathrm{Ni}-(\mathrm{X})$ alloys have been produced by vacuum melting. The chemical compositions, which have been analysed by EDX, are shown in table 1.

After homogenizing at $1200^{\circ} \mathrm{C}$ for 24 hours, the samples are water quenched and afterwards cooled down to liquid nitrogen temperature for one hour.

Table 1: Chemical compositions of the investigated alloys (wt.\%)

\begin{tabular}{|l||c|c|c|c|c|}
\hline & $\mathrm{Fe}$ & $\mathrm{Ni}$ & $\mathrm{Co}$ & $\mathrm{Ti}$ & $\mathrm{C}$ \\
\hline \hline alloy I & bal. & 30,8 & - & - & - \\
\hline alloy II & $"$ & 25,0 & - & - & 0,32 \\
\hline alloy III & $"$ & 27,3 & 15,4 & 3,9 & - \\
\hline
\end{tabular}

To explore the influence of ordered precipitations on the transformation behavior, the Fe-Ni$\mathrm{Co}-\mathrm{Ti}$ - alloy has been aged $\left(600^{\circ} \mathrm{C} / 5 \mathrm{~h}\right)$ before cooling to $-196^{\circ} \mathrm{C}$. During this treatment fine precipitations form in austenite with a $\mathbf{L} 1_{2}$ structure. To determine the reverse- transformation temperatures by DSC specimens of $100 \mathrm{mg}$ have been prepared. During this investigation different heating rates have been selected in the range from $1^{\circ} \mathrm{C} / \mathrm{min}$ up to $60^{\circ} \mathrm{C} / \mathrm{min}$. The austenite transformation temperatures are listed in table 2. Optical and transmission electron microscopy observations of the retransformed DSC- specimens have been done to describe the change in macro- and microstructure.

Table 2: Retransformation temperatures of the alloys depending on heating rates

\begin{tabular}{||c|c|c|c|}
\hline \multirow{2}{*}{ Fe-Ni } & $\begin{array}{c}\text { Heating rate } \\
{\left[{ }^{\circ} \mathrm{C} / \mathrm{min}\right]}\end{array}$ & $\begin{array}{c}\mathrm{A}_{\mathrm{s}} \\
{\left[{ }^{\circ} \mathrm{C}\right]}\end{array}$ & $\begin{array}{c}\mathrm{A}_{\mathrm{f}} \\
{\left[{ }^{\circ} \mathrm{C}\right]}\end{array}$ \\
\hline \hline \multirow{2}{*}{$\mathrm{Fe}-\mathrm{Ni}-\mathrm{C}$} & 1 & 415 & 442 \\
\cline { 2 - 5 } & 60 & 360 & 440 \\
\hline \hline \multirow{2}{*}{$\mathrm{Fe}-\mathrm{Ni}-\mathrm{Co}-\mathrm{Ti}$} & 1 & 489 & 523 \\
\cline { 2 - 5 } & 60 & 465 & 520 \\
\cline { 2 - 5 } & 1 & 150 & 245 \\
\hline
\end{tabular}

\section{Results}

After homogenizing, all investigated alloys are in austenite single phase at room temperature. While cooling to liquid nitrogen temperature the samples completely transform into martensite. With variation of the heating rate different changes in macro- and microstructures are observed (fig.1-4). For a better understanding the presentation of the results is subdivided regarding heating rate and alloys.

\section{a) Heating rate $1^{\circ} \mathrm{C} / \mathrm{min}$}

In alloy I a grain refinement can be observed after retransformation with a heating rate of $1^{\circ} \mathrm{C} / \mathrm{min}$ (fig. 1). The different grains are not clearly separated by grain boundaries. In the areas of the same orientation internal substructures become visible (fig.1a). These structures have a marten- 
sitic appearence. They are characterized by a high dislocation density. As the retransformation has finished and no martensite can be detected by TEM- diffraction, these substructures are called "ghost martensite" in the following.

The effect of grain refinement after reaustenitization becomes more dominant in alloy II. Areas of one orientation are partially needle shaped (fig.1b). "Ghost martensite" as observed in alloy I could not be detected. By TEM investigation carbon precipitations are observed inside the grains and at grain boundaries.

In opposite to these results, the microstructure of alloy III is not influenced by the moderate heating rates after retransformation (fig.4). "Ghost martensite" does not occur. Nevertheless, dislocation structures are observed which are arranged at the former martensite/austenite interfaces. With the exception of metastable coherent $\gamma^{\prime}$ - and the incoherent stable $\eta$-precipitations no other phases could be detected by diffraction.

\section{b) Heating rate $60^{\circ} \mathrm{C} / \mathrm{min}$}

Alloy I, which has been reaustenitizised with a heating rate of $60^{\circ} \mathrm{C} / \mathrm{min}$ is in austenite single phase at room temperature. Inside the grains substructures become more dominant compared to the moderate retransformed sample (fig.2a,3a).

More rapid heating during the retransformation in alloy II lead to a complete austenitic microstructure, too (fig.2b). Along some grains containing "ghost martensite", grains without any substructure become visible. Even at this high heating rates a formation of carbon precipitations has been observed (fig.3b).

Compared to the slowly retransformed samples of alloy III, no difference in microstructure can be observed in the aged condition.

\section{Discussion}

The results of the present investigation lead to the supposition that the retransformation course depends on both heating rates and ordered coherent precipitations.

\section{a) Retransformation of alloy $I\left(1^{\circ} \mathrm{C} / \mathrm{min}, 60^{\circ} \mathrm{C} / \mathrm{min}\right)$}

The microstructure of the moderately reaustenitized samples is characterized by the appearance of "ghost martensite" and small grains without any structure. These observations lead to the supposition that the $\alpha_{d}-\gamma$ - transformation is promoted by lattice shearing and thermally activated processes.

A criterion for lattice shearing is the occurence of the substructures $\left(\gamma_{\mathrm{d}}\right)$ in the retransformed microstructures (fig.1a,2a). Their occurence during moderate heating as well as more rapidly heating indicates that their formation is independent of thermally activated processes. The origin of the "ghost martensite" is still unknown. The high dislocation density of this internal substructures implies that the $\gamma-\alpha_{\mathrm{d}}-\gamma$ - transformation is not completely reversible (fig.3a). This means that irreversible defects have been formed by lattice invariant shear processes. Immobile dislocations of martensite are transformed into austenitic lattice (equ.1). This represents an intermediate stage between no and complete reversibility. Due to the high dislocation density these areas show a different etching behaviour compared with the matrix.

$$
\bar{b}_{\mathrm{bcc}}=\mathrm{a}[001]_{\mathrm{bcc}} \rightarrow \mathrm{a}[001]_{\mathrm{fcc}}=\overline{\mathrm{b}}_{\mathrm{fcc}}
$$


Nickel diffusion is thought to be responsible for thermally activated retransformation in the case of moderate heating. In the temperature range $A_{s}<T<A_{f}$ the existence of both phases martensite and austenite is likely to occur at the same time. Now it can be assumed that nickel diffusion takes place at the martensite/austenite interfaces in direction to the equilibrium /1/. During this process the nickel- diffusion is promoted by high dislocation density of martensite. As a result, the austenite becomes nickel enriched while the nickel content of the martensite decreases. Due to the reduction of nickel the martensitic phase is stabilized and the retransformation temperature $A_{s}$ (table 2) increases. The increasing $A_{s}$ - temperature favours recovery or recrystallization processes of the martensite $\left(\alpha_{\mathrm{r}}\right)$ and the retransformation takes place in a structure with a low lattice defect density /2/. Grain boundaries and interfaces are possible nucleation sites for the thermally activated $\alpha_{d}-\gamma-$ transformation $\left(\gamma_{n}\right)$. The reaction can be described by equ. 2 .

$$
\alpha_{d} \rightarrow \alpha_{r}+\alpha_{d} \rightarrow \gamma_{n}+\gamma_{d}
$$

In the case of more rapid heating the microstructure of the samples is characterized by the occurence of substructures (fig.2a). As the average grain size is not influenced by this treatment it could be assumed that the $\alpha_{d}-\gamma$ - transformation is controlled by lattice shearing $\left(\gamma_{d}\right)$. Dislocations which have formed during martensitic transformation are not annihilated during $\alpha_{d}-\gamma-$ reaction (fig. $3 \mathrm{a}$ ). In opposite to the moderate heating rate, a $\mathrm{Ni}$ - diffusion could be neglected so that there is no change in martensite/austenite- interface relation $/ 3 /$. The reaction in the case of more rapid heating can be described by equ.3.

$$
\alpha_{\mathrm{d}} \rightarrow \gamma_{\mathrm{d}}
$$

\section{b) Slow and more rapid retransformation of alloy $I I\left(1^{\circ} \mathrm{C} / \mathrm{min}, 60^{\circ} \mathrm{C} / \mathrm{min}\right)$}

In the carbon alloyed sample (alloy II) no "ghost martensite" is detected after reaustenitization conducted with moderate heating rate (fig.1b). So it is evident that the transformation course is dominated by diffusion controlled processes. Carbon diffusion is an important factor of influence because of the high diffusion velocity of this alloying element. In contrast, Ni- diffusion can be neglected. Carbon precipitation $\left(\mathrm{M}_{\mathrm{x}} \mathrm{C}_{\mathrm{y}}\right)$ takes place additionally to the recovery process in the martensitic phase $\left(\alpha_{\mathrm{r}}\right)$. During the following retransformation these precipitations act as additional nucleation sites of the austenite $\left(\gamma_{n}\right)$. The reaction can be described by equ. 4 .

$$
\alpha_{d} \rightarrow \alpha_{d}+M_{x} C_{y} \rightarrow \alpha_{r}+M_{x} C_{y} \rightarrow \gamma_{n}+M_{x} C_{y}
$$

A different effect is observed in alloy II in the case of more rapid heating. The observation of the microstructure shows that the retransformation takes place by lattice shearing. Nevertheless, carbon precipitation occurs (fig.3b). As reported in former studies precipitation reactions have been observed even at higher heating rates $/ 4$. Due to the heating rate the particle size is small. It can be assumed that the martensite crystals containing carbides of a critical size are more resistant against transformation by lattice shearing. TEM- investigations have shown that the dislocation density is significantly reduced in grains containing carbon precipitations. Obviously, in these grains a diffusion- controlled retransformation becomes more favourable under energetic aspects. The reaction can be described by equ. 5 .

$$
\alpha_{d} \rightarrow \alpha_{d}+M_{x} C_{y} \rightarrow \gamma_{d}+\gamma_{n}+M_{x} C_{y}
$$

\section{c) Slow and more rapid retransformation of alloy $\mathrm{III}\left(1^{\circ} \mathrm{C} / \mathrm{min}, 60^{\circ} \mathrm{C} / \mathrm{min}\right)$}

During aging coherent metastable $\gamma^{\prime}$-precipitations have formed and therefore the austenite becomes heterogeneous $\left(\gamma_{h}\right)$. Due to the nickel enriched precipitations the nickel content of the 
matrix is reduced which causes an increase of the $\mathrm{M}_{\mathrm{s}}$ - temperature. This effect is compensated by the enormous increase of microhardness and as a result, the transformation temperature decreases (table 2) $15 /$. This means that the retransformation into austenite takes place in a temperature range in which no thermally activated processes are expected. Furthermore, the metastable precipitations have been sheared into martensite $\left(\alpha^{\prime}\right)$ without loosing their coherency to the matrix $\left(\alpha_{\mathrm{dl} 1}\right)$ $/ 6 /$. The energy of the $\alpha_{\mathrm{d}}-\gamma$ - transformation is stored elastically in the material which causes a reduction of plastic deformation in the heterogeneous austenitic phase $\left(\gamma_{\mathrm{db}} \downarrow\right)$. After the $\gamma-\alpha_{\mathrm{d}^{-}}$ transformation the instability of the $\alpha^{\prime}$ - phase increases. This is an additional component to the energy which is required for the retransformation. Due to this effect the $\mathrm{A}_{\mathrm{s}}$ - temperature decreases. Diffusion reactions during reaustenitization can be neglected and therefore the retransformation seems to be almost independent of heating rates. The reaction can be described by equ. 6 .

$$
\alpha_{\mathrm{dh}} \rightarrow \gamma_{\mathrm{h}}+\left(\gamma_{\mathrm{dh}}\right) \downarrow
$$

\section{Conclusion}

Higher heating rates promote a retransformation from martensite into austenite by lattice shearing. In this case thermally activated processes can be neglected during $\alpha_{\mathrm{d}}-\boldsymbol{\gamma}$ - transformation. As a result only a change in microstructure is observed and an internal substructure inside the retransformed grains becomes visible. This "ghost martensite" represents an intermediate stage between irreversibility and reversibility.

Complete reversibility is favoured by additional occurence of coherent metastable precipitations. Due to these particles the microhardness of the austenite is increased and the transformation energy is stored elastically in the material. In addition, the $A_{s}$ - temperature is depressed in a temperature range in which diffusion reactions can be neglected.

\section{References}

[1] Keßler, H., Pitsch, W., Arch. Eisenhüttenw. 39 (1968) 223

[2] Hornbogen, E:, Met, Trans. 10A (1979) 947

[3] Keßler, H., Pitsch, W., Arch. Eisenhüttenw. 38 (1967) 321

[4] Apple, C.A., Krauss, W., Act. Met. 20 (1972) 849

[5] Hornbogen, E., Z. Metallkde. 42 (1984) 741

[6] Hornbogen, E., Phys. stat. sol.(b) 172 (1992) 161
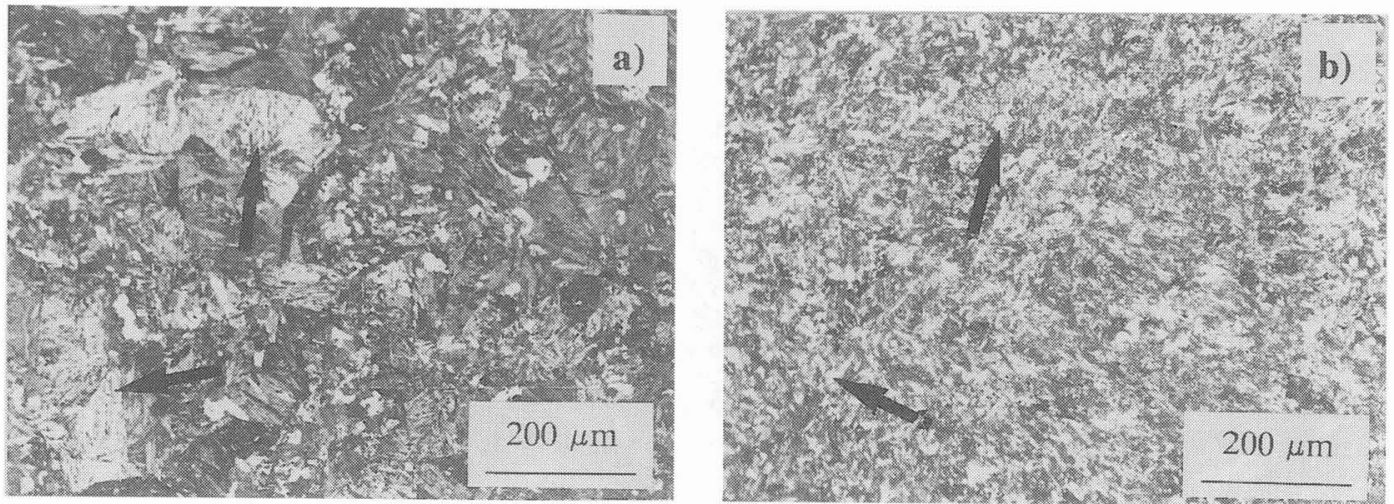

r igure I: Uptical micrograpns ot alloy 1 (a) and alloy II (D) retranstormation during siow neatıng $\left(1^{\circ} \mathrm{C} / \mathrm{min}\right)$ to $\mathrm{T}>\mathrm{A}_{\mathrm{f}}$.

a) Arrows mark "ghost martensite" ( $\gamma_{\mathrm{d}}$, equ.2)

b) Arrows mark grains without substructure ( $\gamma$, equ.4), precipitation of $M_{x} C_{y}$ interferes. 

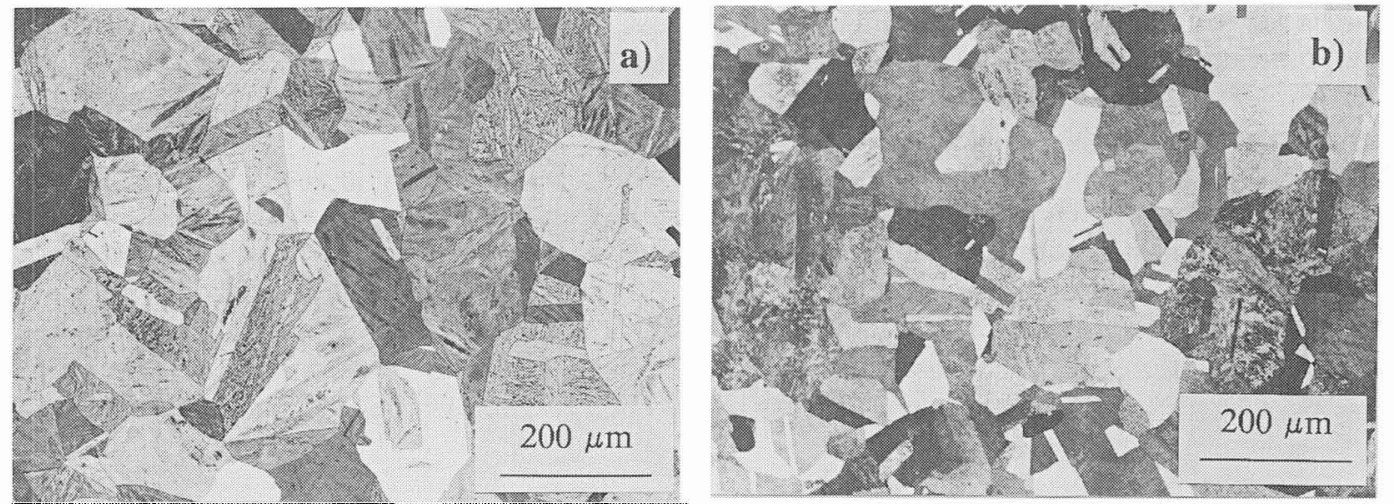

Figure 2: Optical micrographs of alloy I (a) and alloy II (b) retransformation during rapidly heating $\left(60^{\circ} \mathrm{C} / \mathrm{min}\right)$ to $\mathrm{T}>\mathrm{A}_{\mathrm{f}}$.

a) "ghost martensite" $\gamma_{d}$, partially reversible transformation (equ.3)

b) $\gamma_{d}+M_{x} C_{y}$ (equ.5).
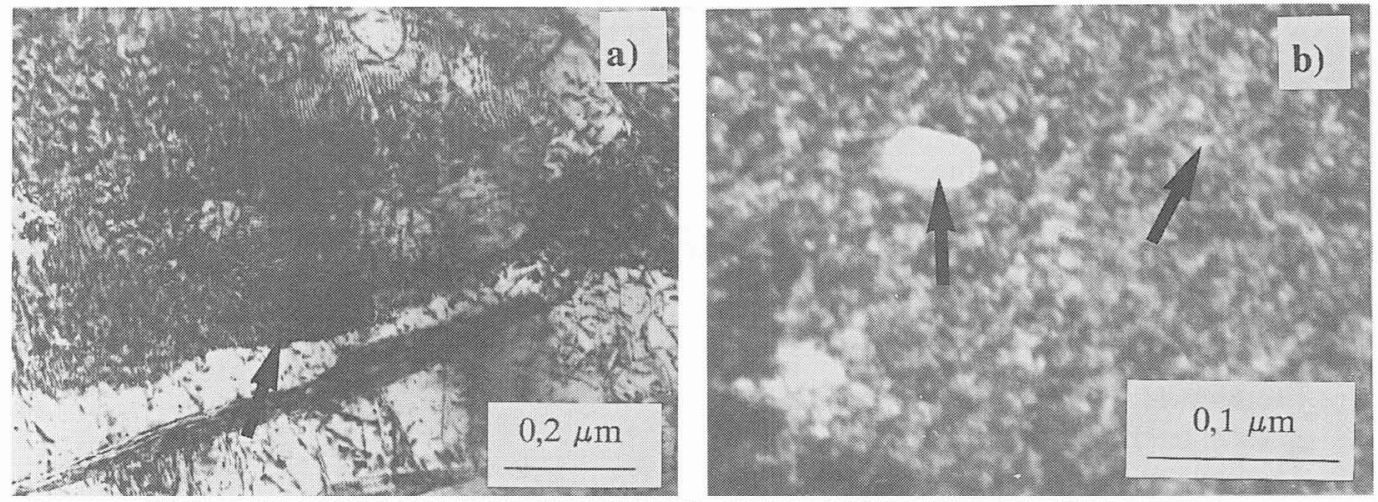

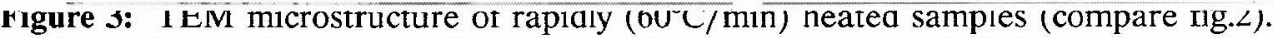

a) alloy I (bright field), arrow indicates origin of "ghost martensite", i. e. defects in austenite.

b) alloy II (dark field), arrows mark carbide particles.
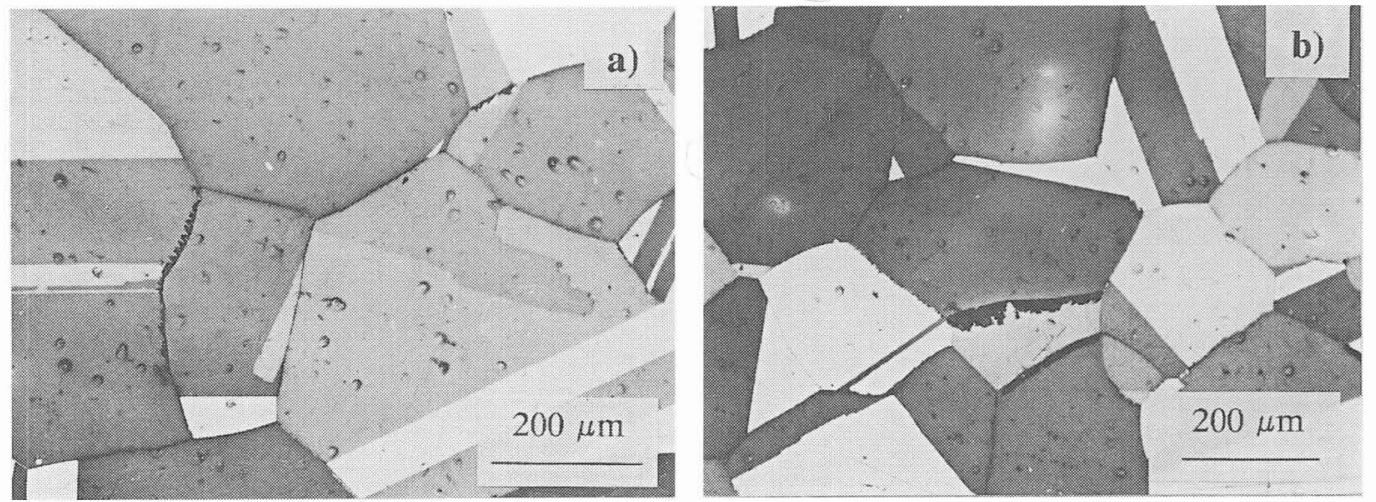

Figure 4: Optical micrographs of alloy 111 , retranstormation during a) slow $\left(1^{\complement} \mathrm{C} / \mathrm{min}\right)$ and b) more rapidly heating $\left(60^{\circ} \mathrm{C} / \mathrm{min}\right)$ to $T>A_{f}$. In both cases the almost perfect austenite $\left(\gamma_{h}\right)$ has been restored by reversible transformation (equ.6). 